\title{
Influences of water deficiency on the productivity of young plants at different sites
}

\author{
KATALIN SÁRDI \\ University of Pannonia, Georgikon Faculty, Department of Horticulture, \\ Keszthely, Hungary \\ sardi@georgikon.hu
}

\section{Summary}

Water deficiency has become one of the most limiting factors of crop production in Hungary as the tendency in annual amounts of precipitation shows a decreasing tendency; therefore, it has become similar to those of Southern Europe. The most significant decrease in precipitation occurs typically during spring, approximately $20 \%$ of the data expressed in the averages of the last century. Studying the relationship between water deficiency as a stress factor and nutrient supply is important in order to improve the production efficiency of crops. Nowadays, this problem receives outstanding attention presented in numerous papers both in Hungary and globally, however, there are several questions yet to be answered.

Our pot experiments were carried out under controlled greenhouse conditions in order to establish new data on these relationships. Experimental soils were typical for Western Transdanubia, taken from long-term field experiments representing four different site characteristics of the region.

It was concluded from the results that drought periods during the early growth stages (i.e. 4-5 weeks after emergence) of plants may result in significant decreases in both dry matter production, nutrient concentrations, nutrient uptake and shoot:root ratios. Better nutrient supply, especially potassium, plays a significant role in reducing the negative effects of water deficiency.

Keywords: water deficiency, nutrient uptake of young plants, pot experiments

\section{Introduction}

In the regions where temperature conditions are favorable for plant growth and development, efficiency of crop production is mostly limited by the amount of precipitation (Mohammad, 1994). It is known that from the 1990' years nutrient balances in Hungary are still negative due to the dramatic decreases of fertilizer use, therefore, yield stability is strongly dependent on the variability of weather conditions at this low level of nutrient input. The main problems of nutrient management can be generally characterized by the capital shortage, consequently the lack of regular soil testing and plant analyses. Furthermore, imbalances in nutrient supply may be also 
unfavorable enhancing the plant responses to drought stress (Levitt, 1972).

It was reported by several authors that in the shortage of soil moisture, the level of potassium supply has statistically significant influence on the water use efficiency and biomass production of crops (Debreczeni and Debreczeniné, 1983; Sárdi and Fülöp, 1994; Sárdi, 2002). These conditions may contribute to the genotype differences in potassium uptake efficiency (Rengel and Damon, 2008).

From the results of long-term experiments, several authors concluded that in soils having good potassium status, water availability were better for crops Gransee (2012) and Thiel (2014). It was also reported that drought stress in extreme crop years can be reduced by applying proper agrotechnics (Dóka, 2011). Although it is generally observed that drought periods during the early growth stages of plants may result significant decreases in both dry matter production and nutrient uptake, quantification of these relationships are still not complete.

The main subject of the experiments was to quantify the influence of potassium and water supply on the growth, development and nutrient uptake of two important crops, corn (Zea mays L.) and sunflower (Helianthus annuus L.). Pot experiments were carried out under controlled greenhouse conditions in order to establish new data on these relationships.

\section{Material and methods}

Our pot experiment series were carried out under greenhouse conditions in pots containing $4 \mathrm{~kg}$ soil for 5 or 6 weeks (growth stadium of plants BBCH 15-18)

Experimental soils were typical for Western Transdanubian sites, taken from long-term field experiments representing variable soil characteristics (labeled by either A, B, C or D). Main characteristics of experimental soils/sites are summarized in Table 1.

Water supply level was maintained at two or three levels: $35 \%, 50 \%$ and $70 \%$ of Water Holding Capacity (WHC) of soils, respectively.

Labels of treatments in the order of NPK are as follows. 000, 111, 112, 113 for corn, and 000, 111, 121 and 222 for sunflower, respectively. Nutrient amounts applied in treatments were calculated either based on crop specific requirements and nutrient supply level in soils. Treatments were applied in four replicates.

Corn (FAO 390-410) and sunflower (Alexandra variety a Pioneer PR64H42 hybrid) were slected as test plants. 
Table 1. Main characteristics of experimental soils

\begin{tabular}{|c|c|c|c|c|c|c|c|c|}
\hline $\begin{array}{l}\text { Soil/site } \\
\text { category }\end{array}$ & $\begin{array}{c}\text { Soil plasticity } \\
\text { Index } \mathrm{K}_{\mathrm{A}}\end{array}$ & $\mathrm{pH}_{\mathrm{H}_{2} \mathrm{O}}$ & $\mathrm{pH}_{\mathrm{KCl}}$ & $\begin{array}{c}\text { Humus } \\
\%\end{array}$ & $\begin{array}{c}\mathrm{N}_{\min } \\
\mathrm{mg} \mathrm{kg}^{-1}\end{array}$ & $\begin{array}{l}\mathrm{AL}-\mathrm{P}_{2} \mathrm{O}_{5} \\
\mathrm{mg} \mathrm{kg}^{-1}\end{array}$ & $\begin{array}{l}\mathrm{AL}-\mathrm{K}_{2} \mathrm{O} \\
\mathrm{mg} \mathrm{kg}^{-1}\end{array}$ & $\begin{array}{c}\text { K Supply } \\
\text { level }\end{array}$ \\
\hline $\begin{array}{l}\text { A } \\
\text { loam/II. }\end{array}$ & 36 & 6.72 & 6.14 & 1.94 & 10.7 & 83.0 & 149.2 & medium \\
\hline $\begin{array}{l}\text { B } \\
\operatorname{loam} / \mathrm{II} .\end{array}$ & 37 & 5.92 & 5.32 & 1.7 & 5.0 & 40.5 & 132.0 & medium \\
\hline $\begin{array}{l}\text { C } \\
\text { clay/III. } \\
\text { D }\end{array}$ & 47 & 4.56 & 4.3 & 2.9 & 12.9 & 96.0 & 267 & medium \\
\hline $\begin{array}{l}\text { sandy } \\
\text { loam/IV. }\end{array}$ & 30.3 & 6.94 & 5.93 & 1.21 & 186 & 186 & 194.1 & good \\
\hline
\end{tabular}

Parameters determined during and at the end of experiments: average plant height $(\mathrm{cm})$, Fresh and DM production of plant shoots and roots, NPK concentrations (\%) and amounts of nutrients taken up by plants (mg per $\mathrm{kg}$ ). Average shoot:root ratios were calculated from dry matter weights. Macronutrient concentrations were compared to literature data of plants recorded in similar growth stages (Reuter and Robinson, 1997). Due to page limitations, DM production, $\mathrm{K}$ concentrations, relative $\mathrm{K}$ uptake of plants and averages of shoot:root ratios were selected for presentation in our paper.

Statistical analyses of experimental results were performed by Analysis of variance (ANOVA). The probability level less than 0.05 were designated as significant.

\section{Results and discussion}

In general, it was observed that drought conditions during the early growth stages (i.e. 4-5 weeks after emergence) of plants may result in significant decreases in each parameters studied.

Corn

Dry matter production and potassium concentrations of corn are presented in Figure 1-2. It was evident from the results obtained that both DM production and nutrient uptake by corn was highly enhanced compared to the unfertilized control, differences were statistically significant.

It was observed that in the heavy textured clay soil (soil C) compared to the same treatments applied in a loam (soil A) even with balanced nutrient supply, reduction in both DM production and potassium concentration of corn at this early growth stage were dramatic due to water deficient conditions. This was obviously due to the unfavorable soil properties in terms of both nutrient and water availability. 
Figure 1. Dry matter (DM) Production of corn grown at 35\%, 50\% and 70\% WHC

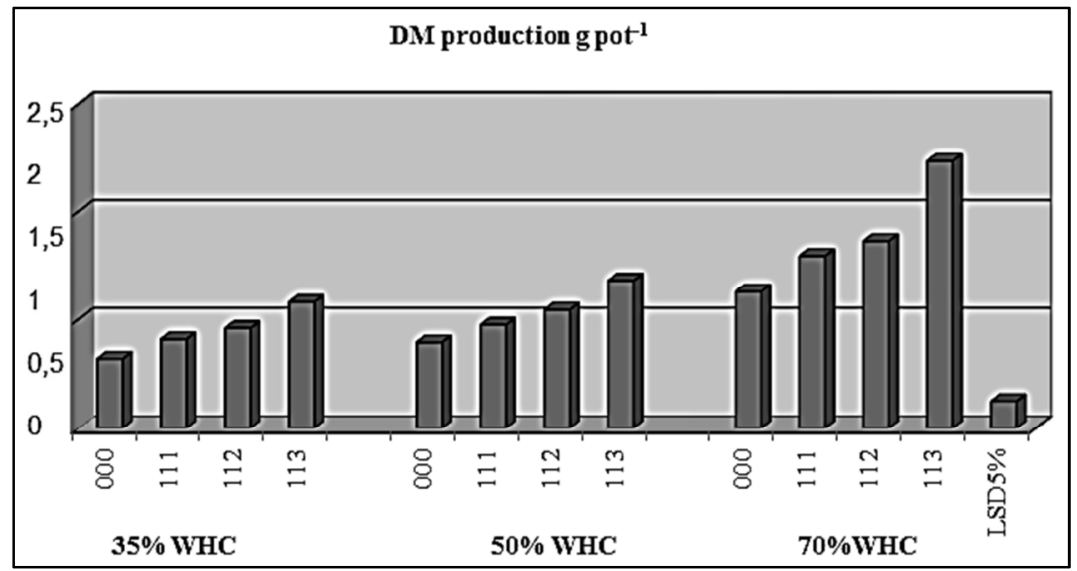

Potassium concentration of control plants grown at the three soil moisture levels were rather similar. Increases in $\mathrm{K}$ concentrations resulted by higher potassium rates were significant at each level of WHC. Potassium concentration of plants was found within the adequate range i.e. $3.0-5.0 \%$ or slightly above that in plants of treatment 113 (Reuter and Robinson, 1997). The highest $\mathrm{K}$ uptake was recorded in treatment 113 at $70 \%$ WHC (data not shown).

Figure 2. Potassium concentration of corn grown at 35\%, 50\% and $70 \%$ WHC

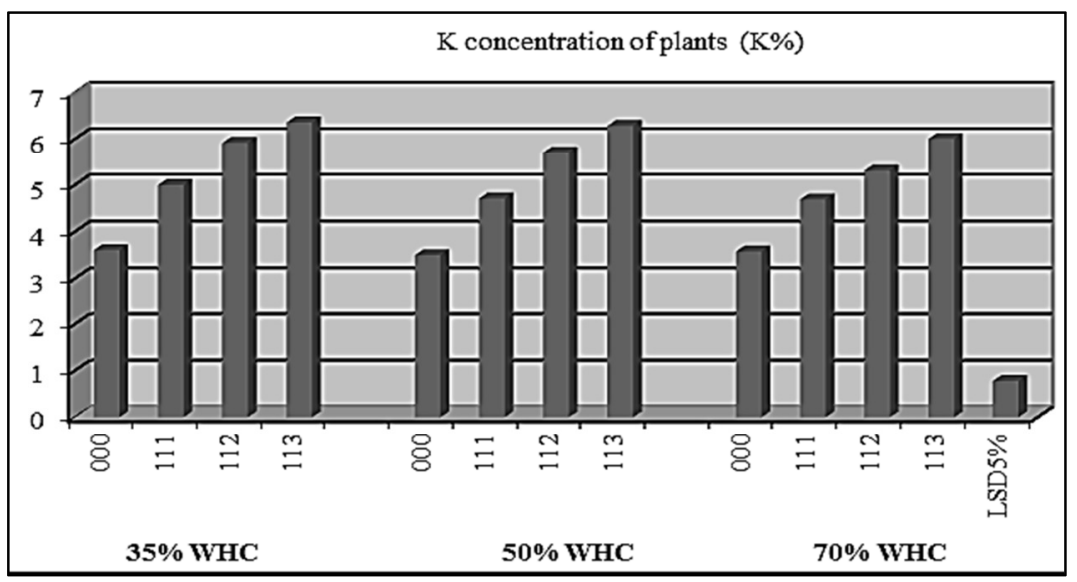

Dry matter production and potassium uptake of corn (BBCH 15-18) grown at $35 \%$ of WHC were expressed in percentages of optimum soil moisture conditions in the different treatments. Expressing these values 
in percentages may help for practical considerations. Results obtained for soil A and soil D are summarized in Table 2. From the results it was evident that balanced nutrient supply can reduce the negative effects of water deficiency.

Table 2. Dry matter (DM) production and potassium uptake of corn grown at 35\% WHC expressed in percentages of optimum soil moisture, $70 \%$ WHC

\begin{tabular}{lcccc}
\hline \multirow{2}{*}{ Treatments } & \multicolumn{2}{c}{ DM production, g pot $^{-1}$} & \multicolumn{2}{c}{ K uptake, mg pot $^{-1}$} \\
\cline { 2 - 5 } & soil A & soil C & soil A & soil C \\
\cline { 2 - 5 } & 76.08 & 65.20 & 83.58 & 66.40 \\
111 & 81.20 & 50.24 & 76.95 & 62.10 \\
112 & 54.39 & 46.00 & 76.72 & 50.80 \\
113 & 41.60 & 38.44 & 49.75 & 46.10 \\
\hline
\end{tabular}

\section{Sunflower}

It was concluded that reduction of DM production were not so strong in the case of this crop, showing that sunflower was more tolerant to drought conditions. These results also represent that better potassium supply proved to be favorable in reducing the negative effect of water deficiency (Figure 3).

Figure 3. Dry matter (DM) production of sunflower grown at 35\%,50\% and $70 \%$ WHC

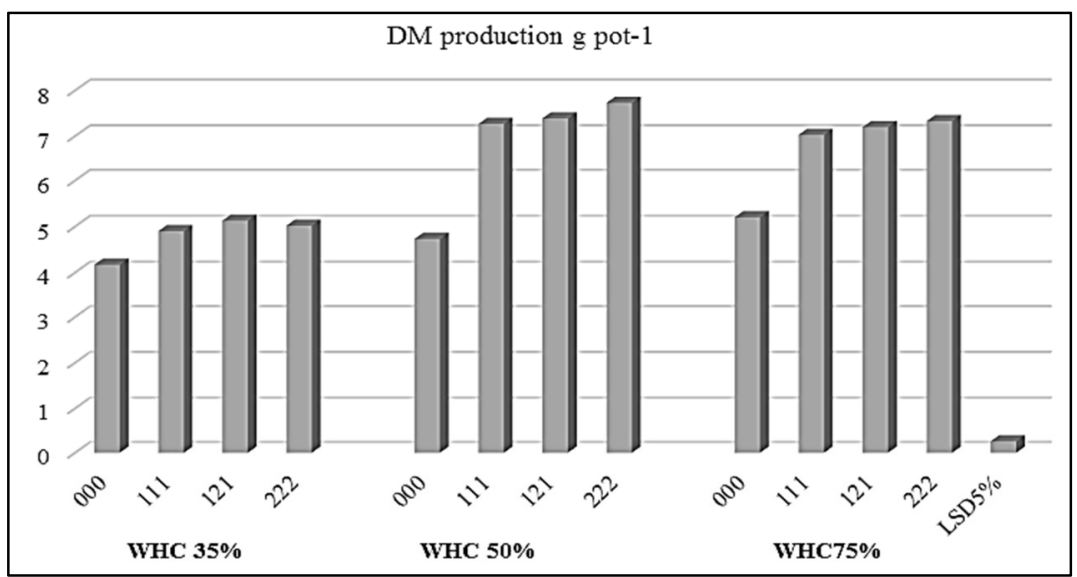

Potassium concentration of plants was found within the adequate range i.e. 3.4-6.6\% or slightly above in treatment 222 (Reuter and Robinson, 1997) (Figure 4). The highest $\mathrm{K}$ uptake was recorded in treatment 222 at $70 \%$ WHC (data not shown). 
Figure 4. Potassium concentration of sunflower grown at 35\%, 50 and $70 \% W H C$

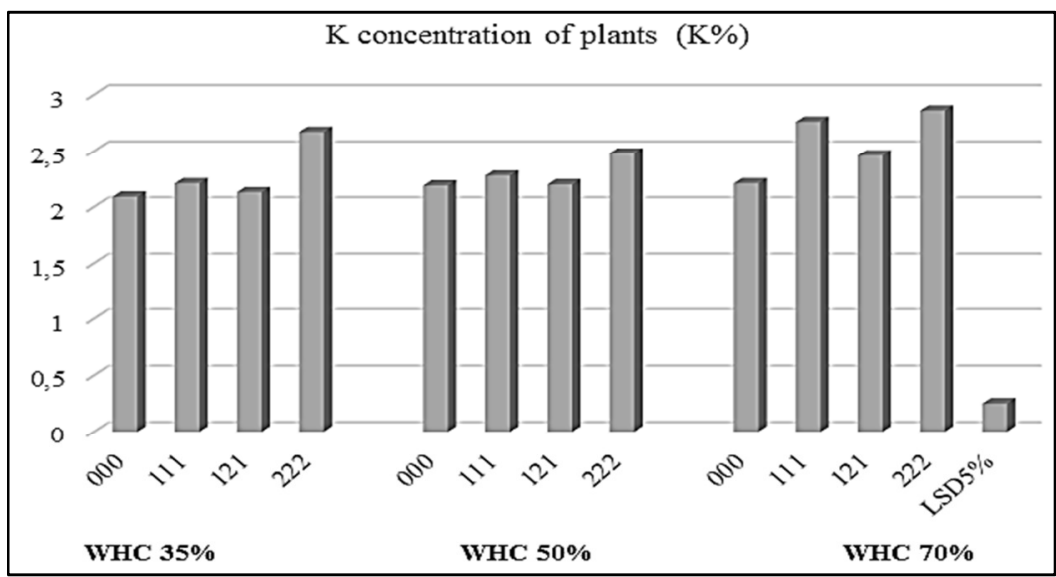

Dry matter production and potassium uptake of sunflower $(\mathrm{BBCH} 16-$ 18) grown at $35 \%$ of WHC were expressed in percentages of optimum soil moisture conditions in the different treatments. Average results were also evaluated in our pot experiment series. Results obtained for soil B (loam, site category II) and a light textured sandy loam, soil D are summarized in Table 3.

Table 3. Dry matter (DM) production and potassium uptake of sunflower grown at $35 \%$ WHC expressed in percentages of optimum soil moisture, $70 \%$ WHC

\begin{tabular}{|c|c|c|c|c|}
\hline \multirow{3}{*}{ Treatments } & \multicolumn{2}{|c|}{ DM production g pot ${ }^{-1}$} & \multicolumn{2}{|c|}{ K uptake mg pot pot $^{-1}$} \\
\hline & \multicolumn{4}{|c|}{$70 \% \mathrm{WHC}=100 \%$} \\
\hline & soil A & soil D & soil A & soil D \\
\hline 000 & 74.3 & 84.3 & 75.30 & 75.30 \\
\hline 111 & 80.5 & 70.5 & 80.30 & 80.30 \\
\hline 121 & 74.6 & 74.6 & 58.36 & 58.36 \\
\hline 222 & 73.1 & 73.1 & 70.76 & 70.76 \\
\hline
\end{tabular}

Shoot:root ratios were also calculated from the dry matter weights. Average values for the experimental sites are summarized in Table 4. From these results it was evident that there were dramatic changes in shoot:root ratios due to soil moisture level. However, responses of sunflower showed that this crop had better tolerance to water deficiency. It was also observed that at better nutrient supply conditions had obviously positive influence on shoot:root ratios of crops in each sites studied. 
Table 4. Average shoot:root ratios of corn and sunflower grown at $35 \%$ and $70 \%$ WHC and expressed in percentages of optimum soil moisture, $70 \%$ WHC

\begin{tabular}{lccc}
\hline \multirow{2}{*}{ Treatments } & $35 \%$ WHC & $70 \%$ WHC & $70 \%$ WHC $=100 \%$ \\
\cline { 2 - 4 } & \multicolumn{3}{c}{ Corn } \\
\hline 000 & 0.88 & 1.83 & 48.1 \\
111 & 1.29 & 1.82 & 70.8 \\
112 & 1.32 & 1.96 & 66.8 \\
113 & 1.49 & 2.11 & 70.6 \\
\hline \multicolumn{4}{c}{} \\
\hline 000 & 0.94 & Sunflower \\
111 & 1.08 & 1.59 & 59.0 \\
221 & 1.35 & 1.43 & 75.0 \\
\hline
\end{tabular}

\section{Conclusions}

It was concluded from the results that drought periods during the early growth stages (i.e. $4-5$ weeks after emergence) of plants may result in significant decreases in both dry matter production and nutrient uptake.

In the soil with medium level of nutrient supply, under water deficient conditions, average DM production and potassium uptake of corn were approximately $45-50$ percent lower compared to those of the plants grown under favorable soil moisture conditions. Responses of sunflower were not so dramatic, reduction of DM production and nutrient uptake were moderate, ranging between 30 and $40 \%$. At the same time, it was also observed that under optimum soil moisture conditions and good soil potassium status, shoot:root ratios of plants were considerable better compared to the control. Average percentages calculated for corn and sunflower were $44.1 \%$ and $31.5 \%$, respectively.

Nutrient status and soil moisture conditions of crops at the early vegetative period are both determinant factors for productivity in terms of expectable yields. At the same time, negative effects of drought can be considerably reduced by better nutrient supply, especially by potassium.

Although results of pot experiments cannot be transferred directly to cropping technologies, statistically significant experimental results obtained under controlled environments may serve as a good background for practical considerations.

\section{References}

Debreczeni B.-Debreczeni B.-né (1983): A tápanyag és vízellátás kapcsolata. Mezőgazdasági Kiadó. Budapest. 
Dóka L. F. (2011): Szélsőséges évjáratok vízháztartásának vizsgálata kukoricaállományban. Növénytermelés. 60. 2: 31-44.

Gransee, A. (2012): K+Mg on Water Use Efficiency. Newagent International. Ref: 218.

Levitt, J. (1972): Responses of Plants to Environmental Stresses. J. Levitt. Academic Press. New York. 698.

Mohammad, P. (1994): Handbook of plant and crop stress. Marcel Dekker Inc. New York.

Rengel, Z.-Damon, P. M. (2008): Crops and genotypes differing efficiency of potassium uptake and use. Physiologia Plantarum.

Reuter, D. J.-Robinson, S. B. (1997): Plant Analysis - an Interpretation Manual CSIRO Publishing. Australia. 226-230.

Sárdi, K.-Fülöp, P. (1994): Relationship between soil potassium level and potassium uptake of corn affected by soil moisture. Communications in Soil Sci. and Plant Anal. 25. 9-10: 1735-1746.

Sárdi K. (2002): A kálium-ellátás és a talajnedvesség hatása a fiatal növények fejlődésére. Acta Agronomica Hungarica. 1: 287-292.

Thiel, H. (2014): Einfluss langjähriger Kaliumdüngung auf Nutzung des Bodenwassers. Pflug und Spaten. 62. 3: 8-9. 